\title{
Depression Treatment in Patients With General Medical Conditions: Results From the CO-MED Trial
}

David W. Morris, $P b D^{1}$

Nitin Budbwar, MD

Mustafa Husain, MD

Stephen R. Wisniewski, PbD ${ }^{3}$

Benji T. Kurian, $M D, M P H^{1}$

James F. Luther, $M A^{3}$

Kevin Kerber, $M D^{4}$

A. Jobn Rush, $M D^{5}$

Madbukar H. Trivedi, $M D^{1}$

'Department of Psychiatry, University of Texas Southwestern Medical Center at Dallas, Dallas, Texas

${ }^{2}$ Department of Family and Community Medicine, University of Texas Southwestern Medical Center at Dallas, Dallas, Texas

${ }^{3}$ Epidemiology Data Center, Graduate School of Public Health, University of Pittsburgh, Pittsburgh, Pennsylvania

${ }^{4}$ Department of Psychiatry, University of Michigan, Ann Arbor, Michigan

${ }^{5}$ Duke-National University of Singapore, Office of Clinical Sciences, Singapore

\section{CORRESPONDING AUTHOR}

David W. Morris, PhD

Department of Psychiatry

The University of Texas Southwestern

Medical Center

5323 Harry Hines Blvd

Dallas, TX 75390-9086

DavidW.Morris@UTSouthwestern.edu

\begin{abstract}
PURPOSE We studied the effect of 3 antidepressant treatments on outcomes (depressive severity, medication tolerability, and psychosocial functioning) in depressed patients having comorbid general medical conditions in the Combining Medications to Enhance Depression Outcomes (CO-MED) trial.
\end{abstract}

METHODS Adult outpatients who had chronic and/or recurrent major depressive disorder (MDD) with and without general medical conditions were randomly assigned in 1:1:1 ratio to 28 weeks of single-blind, placebo-controlled antidepressant treatment with (1) escitalopram plus placebo, (2) bupropion-SR plus escitalopram, or (3) venlafaxine-XR plus mirtazapine. At weeks 12 and 28 , we compared response and tolerability between participants with $0,1,2$, and 3 or more general medical conditions.

RESULTS Of the 665 evaluable patients, $49.5 \%$ reported having no treated general medical conditions, $23.8 \%$ reported having $1,14.8 \%$ reported having 2 , and $11.9 \%$ reported having at least 3 . We found only minimal differences in antidepressant treatment response between these groups having different numbers of conditions; patients with 3 or more conditions reported higher rates of impairment in social and occupational functioning at week 12 but not at week 28. Additionally, we found no significant differences between the 3 antidepressant treatments across these groups.

CONCLUSIONS Patients with general medical conditions can be safely and effectively treated for MDD with antidepressants with no additional adverse effect or tolerability burden relative to their counterparts without such conditions. Combination therapy is not associated with an increased treatment response beyond that found with traditional monotherapy in patients with MDD, regardless of the presence and number of general medical conditions.

Ann Fam Med 2012;10:23-33. doi:10.1370/afm.1316.

\section{INTRODUCTION}

M ajor depressive disorder (MDD) is a psychiatric disorder that is commonly found in patients with a wide range of general medical conditions and that may have a substantial impact on patient functioning. Most of these patients with MDD have a recurrent course ( $>1$ episode), a chronic course (an episode lasting $>2$ years), or both ${ }^{1}$ with incomplete recovery between episodes. ${ }^{2,3}$ This common unremitting course of depression is associated with a significantly worse prognosis and disability. ${ }^{4-6}$ In 2004, the World Health Organization's Global Burden of Disease project ranked unipolar depression (MDD) as the third leading cause of disease burden (in terms of disability-adjusted life-years) worldwide and the leading cause in middle- and high-income countries. ${ }^{7}$

The relationship between general medical conditions and comorbid depression is well documented in the literature ${ }^{8-20}$ Comorbid MDD may 
complicate the management of these conditions. ${ }^{21}$ Assessment is challenging because the symptoms of a primary general medical condition and the related medical treatments (ie, medication adverse effects) for example, low energy, disturbances in sleep, changes in appetite/weight, and perhaps secondary symptoms such as avolition, apathy, and anhedoniaoverlap with the diagnostic symptoms of MDD. ${ }^{22-25}$ Traditional treatments for depression are not as effective in patients with general medical conditions. ${ }^{26,27}$ Specifically, the more such conditions a patient has, the worse the prognosis for the treatment of depressive symptoms.

We explored the relationship between general medical conditions and comorbid depression in a large consecutive series of patients recruited from both primary care and psychiatric practices who entered the Combining Medications to Enhance Depression Outcomes (CO-MED) study's depression treatment protocol (http://www.co-med.org). ${ }^{28}$ The findings reported here address the following questions: (1) Are there differences in overall antidepressant treatment outcomes (in terms of depressive symptom severity, medication tolerability, psychosocial functioning) based on the number of general medical conditions present? and (2) Are there differences in how patients with general medical conditions $(0,1,2, \geq 3)$ and comorbid MDD respond (in terms of depressive symptom severity, medication tolerability, psychosocial functioning) to traditional antidepressant monotherapy vs combination therapy.

\section{METHODS}

\section{Study Overview}

The CO-MED study lasted 7 months, consisting of 12 weeks of acute care and 16 weeks of follow-up treatment. It was a multisite, single-blind, randomized trial that compared the efficacy of traditional selective serotonin reuptake inhibitor (SSRI) monotherapy (escitalopram plus placebo) vs that of 2 antidepressant medication combinations (escitalopram plus bupropion$\mathrm{SR}$, and venlafaxine-XR plus mirtazapine) in patients with chronic and/or recurrent, nonpsychotic MDD. ${ }^{28}$ Patients were blinded, but the clinical research coordinators and physicians were not to maximize safety and to allow physicians to make informed flexible dosing decisions. Escitalopram was selected as a representative SSRI used for monotherapy, the most common first-step medication treatment option. Bupropion was included in the study as a combination agent because it is a dopamine and norepinephrine modulator ${ }^{29}$ widely used to augment SSRIs. ${ }^{30,31}$ The second combination of venlafaxine-XR plus mirtazapine was selected because in combination, these medications affect all 3 major neurotransmitter systems by mechanisms that differ from those of escitalopram plus bupropion-SR. ${ }^{32}$

Patients with and without general medical conditions were randomly assigned to the 3 treatment arms in balanced fashion. The study recruited 665 outpatients with MDD, 335 of whom were being treated for at least 1 general medical condition, from 6 primary care and 9 psychiatric care sites across the Unites States. Study visits were planned at baseline and weeks $1,2,4,6,8,10,12,16,20,24$, and 28 . The research protocol was approved and monitored by the institutional review boards of the University of Texas Southwestern Medical Center at Dallas, the University of Pittsburgh, and each participating regional center. The study was also monitored by an independent data safety and monitoring board.

\section{Participants}

Broad inclusion and minimal exclusion criteria were used to ensure a representative participant sample. Patients with and without general medical conditions were enrolled; however, the conditions had to be medically stable as reported by their primary treating physician. Enrollees were outpatients aged 18 to 75 years who met Diagnostic and Statistical Manual of Mental Disorders (Fourth Edition, Text Revision) (DSM$I V-T R)^{33}$ criteria for nonpsychotic MDD that was either recurrent ( $\geq 1$ prior major depressive episode) or chronic (current major depressive episode present for $\geq 2$ years) based on a clinical interview and the Mini International Neuropsychiatric Interview (MINI). ${ }^{34}$ Eligibility also required that the index episode had to be ongoing for at least 2 months, and that patients have a score of at least 16 on the 17 -item Hamilton Rating Scale for Depression. ${ }^{35}$ A full listing of exclusion criteria is available on the CO-MED Web site (http://www.co-med.org).

\section{Antidepressant Treatments}

The trial used measurement-based care to enable personally tailored and vigorous antidepressant dosing. ${ }^{36}$ Dosage adjustments were based on symptom severity using the 16-item Quick Inventory of Depressive Symptomatology-Clinician rated $\left(\mathrm{Q} I D S-\mathrm{C}_{16}\right)^{37}$ and tolerability was assessed using the Frequency, Intensity, and Burden of Side Effects Rating (FIBSER), ${ }^{38}$ given in Supplemental Appendix 1 (available at http://www. annfammed.org/content/10/1/23/suppl/DC1), and the Systematic Assessment for Treatment Emergent Events-Systematic Inquiry (SAFTEE-SI) ${ }^{39}$ obtained at each treatment visit.

Patients were stratified by clinical site and randomly assigned to 3 treatment groups in 1:1:1 ratio 
using a Web-based randomization system. ${ }^{40}$ Dosing schedules were based on previous efficacy and tolerability data. ${ }^{41-44}$ Doses were increased only in the context of acceptable adverse effects. Patients could exit the study if they experienced unacceptable or intolerable adverse effects that could not be resolved with dose reduction or medication treatment.

\section{Escitalopram Plus Placebo}

Escitalopram dosing started at $10 \mathrm{mg} / \mathrm{d}$. At week 2, 1 placebo capsule was added. At week 4 and beyond, if a patient's QIDS-C $_{16}$ score was greater than 5 (adverse effects allowing), the escitalopram dose could be increased to $20 \mathrm{mg} / \mathrm{d}$ (maximum dose) and the placebo dose could be increased to 2 capsules.

\section{Bupropion-SR Plus Escitalopram}

Bupropion-SR was started at $150 \mathrm{mg} / \mathrm{d}$, and increased to $300 \mathrm{mg} / \mathrm{d}$ after 1 week. At the week 2 visit, blinded escitalopram $10 \mathrm{mg} / \mathrm{d}$ was added. At week 4 and beyond, if a patient's QIDS- $\mathrm{C}_{16}$ score was greater than 5 (adverse effects allowing), the bupropion-SR dose could be increased to $400 \mathrm{mg} / \mathrm{d}$ (maximum dose), and the escitalopram dose could be increased to $20 \mathrm{mg} / \mathrm{d}$.

\section{Venlafaxine-XR Plus Mirtazapine}

Venlafaxine-XR was started at $37.5 \mathrm{mg} / \mathrm{d}$ for 3 days and then increased to $75 \mathrm{mg} / \mathrm{d}$. At week 1, the venlafaxine-XR dose was increased to $150 \mathrm{mg} / \mathrm{d}$. At week 2, blinded mirtazapine $15 \mathrm{mg} / \mathrm{d}$ was added. At week 4 and beyond, if a patient's QIDS- $\mathrm{C}_{16}$ score was greater than 5 (adverse effects allowing), the venlafaxine-XR dose could be increased to $225 \mathrm{mg} / \mathrm{d}$, then again at a subsequent visit to $300 \mathrm{mg} / \mathrm{d}$ (maximum dose); in a similar fashion, the mirtazapine dose could be increased to 30 $\mathrm{mg} / \mathrm{d}$, then to $45 \mathrm{mg} / \mathrm{d}$ (maximum dose).

\section{Measures}

Patients' social, demographic, and clinical (medical and psychiatric) features were collected at baseline using standard forms. The clinician-rated MINI was used to evaluate mood disorders and screen for psychosis, and the self-report Psychiatric Diagnostic Screening Questionnaire ${ }^{45}$ was used to established the presence of anxiety disorders, substance use disorders, eating disorders, and hypochondriasis. ${ }^{46}$ Suicidal risk was assessed with the Concise Health Risk Tracking

tool, given in Supplemental Appendix 2 (available An at http://www.annfammed.org/content/10/1/23/ suppl/DC1). All CO-MED clinical research coordinators were certified to administer the clinician-rated assessment used for screening, baseline, and regular study visits. The training and certification consisted of 3 steps: (1) didactic training, (2) interrater reliability certification, and (3) written examination (see the COMED Clinical Procedures Manual for details, http://www. co-med.org).

General medical comorbidity burden was quantified using the Self-Administered Comorbidity Questionnaire, a self-report that assesses the presence of medical problems, their severity, and whether the condition limits functioning. ${ }^{47}$ The medical conditions specified include heart disease, high blood pressure, lung disease, diabetes, gastrointestinal tract disorders, kidney disease, liver disease, anemia or other blood disease, cancer, arthritis, thyroid disease, and chronic back pain. Respondents have the option of adding 3 additional conditions. An individual can receive a maximum of 3 points for each medical condition (1 point for its presence, 1 point for its treatment, and 1 point if it limits activities). For this study, we defined a general medical condition as one that was present and being treated.

Outcome assessments were collected at baseline and at all subsequent treatment visits. The primary outcome, depressive symptom severity, was based on the 16-item Quick Inventory of Depressive Symptomatology-Self-Report (QIDS-SR 16 ), given in Supplemental Appendix 3 (available at http://www.annfammed. org/content/10/1/23/suppl/DC1). ${ }^{37}$ Secondary outcomes of tolerability as measured by the FIBSER and SAFTEE-SI, and social and occupational functioning as measured by the Work and Social Adjustment Scale (WSAS), ${ }^{48}$ were collected at each clinic visit through the entire study period.

\section{Statistical Analyses}

The CO-MED study was powered to detect differences between the 3 antidepressant treatment arms. Power estimates indicated that 220 patients per group would provide adequate power $(.80$, with $\alpha=.05)$ to detect a $12.8 \%$ difference between the combination treatments and monotherapy during the acute phase, and $11.2 \%$ during the continuation phase. Power estimates for the planned secondary analysis of treatments stratified by number of general medical conditions were not used to determine sample size. We computed descriptive statistics, including measures of central tendency and dispersion, for continuous data and estimated frequency distributions for categorical data. The appropriate parametric test (ie, $t$ test) or nonparametric tests (ie, $\chi^{2}$, Wilcoxon tests) were used to ensure a balanced distribution of the social, demographic, psychiatric, and medical characteristics among patients with and without general medical conditions.

At 12 and 28 weeks, we compared unadjusted and adjusted outcomes among patients with $0,1,2$, and 3 
or more general medical conditions using regression models. The type of regression models varied by outcome and included linear regression, logistic regression, ordinal logistic regression, and negative binomial regression models. Potential confounders were identified using a stepwise logistic regression model with an indicator of general medical conditions as the outcome and all other baseline characteristics as independent variables. Those variables that remained in the final stepwise model were considered as potential confounders in the adjusted models. The moderating effect of general medical conditions on treatment was evaluated on 2 outcomes, severity of depression (QIDS-SR ${ }_{16}$ ), and adverse effect burden (FIBSER burden), at 12 and 28 weeks. For severity of depression, we fit a linear regression model; for adverse effect burden, we fit an ordinal logistic regression model. Both models included main effects for treatment and general medical conditions, as well as the 2-way interaction between treatment and general medical conditions. All analyses are considered to be exploratory in nature, and a type I error or $P$ value of less than .05 was used as a threshold to identify statistical significance. A threshold of $P$ less than .0083 was used to identify statistical significance of post hoc comparisons in the adjusted models.
Table 1. Patient Characteristics at Baseline by Number of General Medical Conditions

\begin{tabular}{|c|c|c|c|c|}
\hline \multirow[b]{2}{*}{ Characteristic } & \multicolumn{4}{|c|}{ No. of General Medical Conditions } \\
\hline & $\begin{array}{c}0 \\
(n=328)\end{array}$ & $\begin{array}{c}1 \\
(n=158)\end{array}$ & $\begin{array}{c}2 \\
(n=98)\end{array}$ & $\begin{array}{c}\geq 3 \\
(n=79)\end{array}$ \\
\hline & \multicolumn{4}{|c|}{ No. (\%) } \\
\hline \multicolumn{5}{|l|}{ Clinical setting } \\
\hline Primary & $140(42.7)$ & $99(62.7)$ & $58(59.2)$ & $49(62.0)$ \\
\hline Psychiatric & $188(57.3)$ & $59(37.3)$ & $40(40.8)$ & $30(38.0)$ \\
\hline Current MDD chronic ${ }^{c}$ & $160(49.1)$ & $85(53.8)$ & $65(66.3)$ & $57(72.2)$ \\
\hline \multicolumn{5}{|l|}{ Sex } \\
\hline Male & $96(29.3)$ & $47(29.7)$ & $35(35.7)$ & $34(43.0)$ \\
\hline Female & $232(70.7)$ & $111(70.3)$ & $63(64.3)$ & $45(57.0)$ \\
\hline \multicolumn{5}{|l|}{ Race } \\
\hline White & $229(72.7)$ & $99(63.9)$ & $58(63.0)$ & $44(55.7)$ \\
\hline Black & $64(20.3)$ & $48(31.0)$ & $29(31.5)$ & $32(40.5)$ \\
\hline Other & $22(7.0)$ & $8(5.2)$ & $5(5.4)$ & $3(3.8)$ \\
\hline Hispanic ethnicity & $52(15.9)$ & $24(15.2)$ & $18(18.4)$ & $7(8.9)$ \\
\hline \multirow[t]{2}{*}{ Employed } & $179(54.6)$ & $88(55.7)$ & $45(45.9)$ & $19(24.1)$ \\
\hline & \multicolumn{4}{|c|}{ Mean (SD) } \\
\hline Age, y & $37.5(12.6)$ & $44.7(11.7)$ & $48.8(10.6)$ & $52.8(9.3)$ \\
\hline Education, y & $14.1(3.0)$ & $13.8(3.0)$ & $13.3(2.8)$ & $12.7(2.8)$ \\
\hline \multicolumn{5}{|l|}{ MDD features } \\
\hline Number of prior antidepressants & $1.5(1.6)$ & $1.5(1.8)$ & $1.8(2.1)$ & $1.8(1.6)$ \\
\hline Duration of current episode, mo & $51.1(91.6)$ & $58.0(94.2)$ & $86.4(135.0)$ & $83.3(126.0)$ \\
\hline Number of prior episodes & $9.8(21.3)$ & $9.2(19.1)$ & $8.7(21.7)$ & $5.9(12.5)$ \\
\hline Age at first episode, $y$ & $20.0(11.9)$ & $25.9(14.1)$ & $28.0(14.5)$ & $31.5(16.5)$ \\
\hline \multicolumn{5}{|l|}{ Test scores } \\
\hline WSAS score & $27.0(8.6)$ & $25.4(9.0)$ & $27.2(9.3)$ & $29.2(8.7)$ \\
\hline SCQ score & $1.0(1.3)$ & $3.2(1.2)$ & $5.8(1.5)$ & $10.6(3.1)$ \\
\hline QIDS-SR $_{16}$ score & $15.7(4.3)$ & $15.1(4.2)$ & $15.3(4.6)$ & $15.5(3.9)$ \\
\hline
\end{tabular}

$\mathrm{MDD}=$ major depressive disorder; QIDS-SR $_{16}=16$-item Quick Inventory of Depressive Symptomatology-Self-Report; $S C Q=$ Self-administered Comorbidity Questionnaire; WSAS = Work and Social Adjustment Scale.

Notes: WSAS scores range from 0 to 40, with higher scores indicating greater levels of impairment. SCQ scores range from 0 to 45, with higher scores indicating greater number of disorders and greater levels of impairment. QIDS scores range from 0 to 27, with higher scores indicating greater levels of depression.

${ }^{a} \chi^{2}$. The $\chi^{2}$ for continuous measures indicates Kruskal-Wallis test.

b The post hoc comparisons were significant after Bonferroni correction $(P<.0083)$.

c Current episode of MDD ongoing for at least 2 years.

${ }^{\mathrm{d}} \chi^{2}{ }_{6}$.

e $F_{3,659}$.

${ }^{\mathrm{f}} \mathrm{F}_{3,636}$.

${ }^{g} F_{3,640}$.

\section{RESULTS}

\section{Patient Characteristics}

Of the 665 evaluable patients, 328 (49.5\%) reported having no general medical conditions, 158 (23.8\%) reported having 1, $98(14.8 \%)$ reported having 2 , and $79(11.9 \%)$ reported having at least 3 . (Two participants did not complete the SCQ.) There were several significant differences between participants according to the number of general medical conditions (Table 1). Patients with such conditions more often sought treatment in primary care vs psychiatric care settings. African American patients more commonly had 3 or more conditions. The frequency of single and multiple conditions increased with age. Years of education were inversely related to the number of reported conditions. Patients with 3 or more conditions had significantly greater social and occupational impairment. Those with conditions had a later age of onset of depression. Patients with 2 or more conditions reported a significantly longer current depressive episode. The incidence of chronic depression (defined 
and week 12, but not at week 28 . We

found no significant differences in symptom severity or tolerability between the groups having different numbers of conditions at weeks 12 and 28 .

\begin{tabular}{|c|c|c|c|c|c|c|c|}
\hline \multirow{2}{*}{$\begin{array}{c}\text { Test } \\
\text { Statistic } \\
\end{array}$} & \multicolumn{7}{|c|}{$P$ Values } \\
\hline & All & 0 vs 1 & 0 vs 2 & 0 vs $\geq 3$ & 1 vs 2 & 1 vs $\geq 3$ & 2 vs $\geq 3$ \\
\hline $23.8^{a}$ & $<.001$ & $<.001^{b}$ & $.004^{b}$ & $.002^{\mathrm{b}}$ & .58 & .09 & .70 \\
\hline $19.2^{\mathrm{a}}$ & .001 & .33 & $.003^{b}$ & $<.001^{b}$ & .048 & $.007^{b}$ & .41 \\
\hline $6.5^{\mathrm{a}}$ & .09 & - & - & - & - & - & - \\
\hline $17.0^{\mathrm{d}}$ & .009 & .04 & .08 & $.001^{\mathrm{b}}$ & .99 & .34 & .45 \\
\hline $3.3^{\mathrm{a}}$ & .34 & - & - & - & - & - & - \\
\hline $26.7^{\mathrm{a}}$ & $<.001$ & .82 & .13 & $<.001^{b}$ & .13 & $<.001^{b}$ & $.003^{b}$ \\
\hline $51.7^{\mathrm{e}}$ & $<.001$ & $<.001^{b}$ & $<.001^{\mathrm{b}}$ & $<.001^{b}$ & $.001^{b}$ & $<.001^{\mathrm{b}}$ & .01 \\
\hline $5.9^{f}$ & $<.001$ & .25 & .02 & $<.001^{\mathrm{b}}$ & .23 & $.006^{\mathrm{b}}$ & .12 \\
\hline $5.1^{\mathrm{a}}$ & .17 & - & - & - & - & - & - \\
\hline $20.6^{a}$ & $<.001$ & .23 & $.002^{\mathrm{b}}$ & $.001^{\mathrm{b}}$ & .055 & $.008^{\mathrm{b}}$ & .47 \\
\hline $4.8^{\mathrm{a}}$ & .19 & - & - & - & - & - & - \\
\hline $51.1^{\mathrm{a}}$ & $<.001$ & $<.001^{b}$ & $<.001^{\mathrm{b}}$ & $<.001^{\mathrm{b}}$ & .25 & .02 & .17 \\
\hline $10.9^{a}$ & .01 & .09 & .69 & .02 & .09 & $.001^{\mathrm{b}}$ & .14 \\
\hline $493.7^{\mathrm{a}}$ & $<.001$ & $<.001^{\mathrm{b}}$ & $<.001^{\mathrm{b}}$ & $<.001^{\mathrm{b}}$ & $<.001^{b}$ & $<.001^{\mathrm{b}}$ & $<.001^{\mathrm{b}}$ \\
\hline $0.7^{9}$ & .55 & - & - & - & - & - & - \\
\hline
\end{tabular}

\section{Outcomes by Antidepressant Treatment}

We did not find any differences in outcomes between antidepressant monotherapy and either of the antidepressant combination therapies, regardless of the number of general medical conditions a patient had (Table 3). Specifically, within each group having a given number of conditions, the 3 treatments did not differ significantly with respect to any of the measures of efficacy or tolerability assessed, at either week 12 or week 28.

\section{DISCUSSION}

Past studies have suggested that patients with general medical conditions are less responsive to antidepressant treatment. ${ }^{49-56}$ Our finding of an almost complete lack of statistical differences in outcome measures (efficacy and tolerability) between patients with differing numbers of conditions may, however, indicate that patients with and without such conditions can receive equally safe and effective treatment for their MDD with antidepressant medications without risk of additional adverse effects or antidepressant intolerability. Additionally, our finding of a lack of statistical differences in outcome measures between patients stratified by number of conditions and treatment received indicates that, as assessed in our sample, combination

as a current episode present for $\geq 2$ years) increased as the number of conditions increased; however, the level of depressive severity did not differ between groups having different numbers of conditions.

\section{Outcomes by Number of Medical Conditions}

We found limited differences in overall MDD treatment outcomes according to the number of general medical conditions patients had (Table 2). Patients with 3 or more conditions reported higher rates of impairment in social and occupational functioning (WSAS) at baseline antidepressant therapy had no additional benefit over SSRI monotherapy for patients with general medical conditions and comorbid, chronic or recurrent MDD.

Treatment programs and guidelines have been developed, studied, and widely disseminated specifically targeting the treatment of MDD in primary care settings. ${ }^{57-61}$ Past studies have identified barriers to the adoption and integration of depression screening and treatment guidelines in primary care settings. ${ }^{62}$ If depression treatment guidelines are implemented, however, outpatient treatment outcomes for depres- 
Table 2. Week 12 and 28 Outcome Measures by Number of General Medical Conditions

\begin{tabular}{|c|c|c|c|c|c|c|c|c|}
\hline \multirow[b]{2}{*}{ Measure } & \multicolumn{4}{|c|}{ No. of General Medical Conditions } & \multicolumn{4}{|c|}{ Unadjusted } \\
\hline & $\begin{array}{c}0 \\
(n=328)\end{array}$ & $\begin{array}{c}1 \\
(n=158)\end{array}$ & $\begin{array}{c}2 \\
(n=98)\end{array}$ & $\begin{aligned} & \geq 3 \\
(n & =79)\end{aligned}$ & 0 vs 1 & 0 vs 2 & 0 vs $\geq 3$ & $P$ Value \\
\hline & \multicolumn{4}{|c|}{ No. (\%) } & \multicolumn{4}{|c|}{ Odds Ratio } \\
\hline \multicolumn{9}{|l|}{ Week 12} \\
\hline Exited acute phase & $90(27.4)$ & $47(29.7)$ & $25(25.5)$ & $19(24.1)$ & 1.12 & 1.01 & 0.85 & .88 \\
\hline Remission ${ }^{b}$ & 135 (41.2) & $60(38.0)$ & 37 (37.8) & $24(30.4)$ & 0.90 & 0.95 & 0.58 & .29 \\
\hline Last QIDS-SR $16<6$ & $129(39.6)$ & $55(34.8)$ & $35(36.5)$ & $23(29.1)$ & 0.84 & 1.08 & 0.68 & .44 \\
\hline Response $^{c}$ & $172(54.8)$ & $77(50.0)$ & $51(54.3)$ & $34(43.0)$ & 0.80 & 1.03 & 0.64 & .28 \\
\hline Last WSASd & - & - & - & - & 1.26 & 1.40 & 2.35 & .005 \\
\hline Maximum FIBSER Frequency & - & - & - & - & 1.05 & 1.04 & 0.81 & .79 \\
\hline Maximum FIBSER Intensity & - & - & - & - & 1.04 & 0.84 & 0.70 & .43 \\
\hline Maximum FIBSER Burden & - & - & - & - & 1.12 & 0.83 & 0.89 & .69 \\
\hline At least 1 SAE & $12(3.7)$ & $7(4.4)$ & $5(5.1)$ & $3(3.8)$ & 0.61 & 1.45 & 0.36 & .53 \\
\hline \multicolumn{9}{|l|}{ Week 28} \\
\hline Exited continuation phase & 123 (37.5) & $60(38.0)$ & 37 (37.8) & $23(29.1)$ & 0.92 & 0.99 & 0.68 & .58 \\
\hline Remission ${ }^{b}$ & $160(48.8)$ & $69(43.7)$ & $38(38.8)$ & $31(39.2)$ & 0.87 & 0.71 & 0.67 & .35 \\
\hline Last QIDS-SR $16<6$ & $156(48.4)$ & $69(43.7)$ & $35(36.1)$ & $32(40.5)$ & 0.82 & 0.69 & 0.70 & .35 \\
\hline Response $^{c}$ & $188(60.6)$ & $93(60.4)$ & $51(53.7)$ & $42(53.2)$ & 0.92 & 0.89 & 0.70 & .62 \\
\hline Last WSASd & - & - & - & - & 1.15 & 1.31 & 1.70 & .14 \\
\hline Maximum FIBSER Frequency & - & - & - & - & 1.06 & 1.09 & 0.86 & .85 \\
\hline Maximum FIBSER Intensity & - & - & - & - & 1.02 & 0.89 & 0.80 & .77 \\
\hline Maximum FIBSER Burden & - & - & - & - & 1.13 & 0.87 & 1.09 & .79 \\
\hline \multirow[t]{2}{*}{ At least $1 \mathrm{SAE}$} & $20(6.1)$ & $9(5.7)$ & $11(11.2)$ & $6(7.6)$ & 0.56 & 1.88 & 0.80 & .17 \\
\hline & \multicolumn{4}{|c|}{ Mean (SD) } & \multicolumn{4}{|c|}{$\beta$ Coefficient } \\
\hline \multicolumn{9}{|l|}{ Week 12} \\
\hline Last QIDS-SR ${ }_{16}$ & $7.8(5.3)$ & $8.1(5.3)$ & $8.5(6.1)$ & $9.1(5.0)$ & 0.425 & 0.390 & 1.230 & .37 \\
\hline$\%$ QIDS-SR ${ }_{16}$ change & $-48(34.8)$ & $-47(30.2)$ & $-44(36.7)$ & $-39(35.4)$ & 1.561 & 3.967 & 9.238 & .21 \\
\hline Last SAFTEE-SI N worse & $5.1(5.3)$ & $4.7(4.5)$ & $5.7(5.1)$ & $5.7(5.3)$ & -0.017 & 0.017 & 0.179 & .28 \\
\hline \multicolumn{9}{|l|}{ Week 28} \\
\hline Last QIDS-SR ${ }_{16}$ & $7.3(5.5)$ & $7.3(5.3)$ & $8.4(6.2)$ & $8.3(5.4)$ & 1.043 & 1.103 & 1.234 & .31 \\
\hline$\%$ QIDS-SR ${ }_{16}$ change & $-52(35.4)$ & $-52(30.6)$ & $-45(37.0)$ & $-44(38.8)$ & -0.595 & 5.387 & 8.716 & .17 \\
\hline Maximum SAFTEE-SI N worse & $9.9(6.9)$ & $9.6(5.8)$ & $10.6(7.0)$ & $11.3(6.6)$ & 1.037 & 1.085 & 1.183 & .32 \\
\hline Last SAFTEE-SI N worse & $4.7(5.3)$ & $4.5(4.7)$ & $6.0(5.7)$ & $5.4(5.6)$ & 0.035 & 0.329 & 0.211 & .07 \\
\hline
\end{tabular}

FIBSER = Frequency, Intensity and Burden of Side Effects Rating; QIDS-SR $_{16}=16$-item Quick Inventory of Depressive Symptomatology-Self-Report; SAE = serious adverse event; SAFTEE-SI = Systematic Assessment for Treatment Emergent Events-Systematic Inquiry; WSAS = Work and Social Adjustment Scale.

Notes: WSAS scores range from 0 to 40, with higher scores indicating greater levels of impairment. SCQ scores range from 0 to 45 , with higher scores indicating greater number of disorders and greater levels of impairment. QIDS-SR ${ }_{16}$ scores range from 0 to 27, with higher scores indicating greater levels of depression. FIBSER scores range from 0 to 6 for each of the indexes.

a Adjusted for treatment, age, education, employment, age at first episode, body mass index, and systolic blood pressure (see Supplemental Table 1, available at http://www.annfammed.org/content/10/1/23/suppl/DC1).

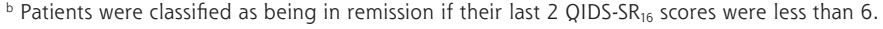

c Patients were classified as having a response if they had a decrease in QIDS-SR ${ }_{16}$ score of at least 50\% from baseline.

${ }^{d}$ An extremely nonnormal distribution required binning.

e Significant after Bonferroni correction $(P<.0083)$.

sion in primary care and specialty care are the same. ${ }^{63}$ Not surprisingly, participants with general medical conditions and comorbid MDD were more likely to be treated for depression by their primary care physician than a psychiatric care professional. This greater likelihood of treatment in primary care could occur for a variety of reasons, the most obvious being that patients with general medical conditions and comorbid MDD may prefer to be treated by a single physician rather than use a separate mental health professional for their depression. Our study's findings suggest that when comparing outcomes between primary and specialty care settings, the number of general medical conditions may need to be adjusted for in the final analysis.

The baseline clinical distinctions associated with the presence of single and multiple general medical conditions in patients with comorbid MDD were 


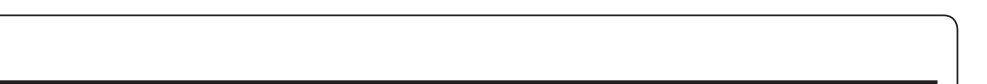

Adjusted $^{\mathrm{a}}$

\begin{tabular}{cccc}
0 vs 1 & 0 vs 2 & 0 vs $\geq 3$ & $P$ Value \\
\hline & Odds Ratio \\
\hline
\end{tabular}

\begin{tabular}{|c|c|c|c|}
\hline 1.31 & 1.12 & 0.94 & .69 \\
\hline 0.89 & 0.98 & 0.67 & .62 \\
\hline 0.86 & 1.15 & 0.82 & .72 \\
\hline 0.89 & 1.28 & 0.81 & .55 \\
\hline 1.34 & 1.40 & $2.17^{e}$ & .04 \\
\hline 1.29 & 1.21 & 1.09 & .65 \\
\hline 1.34 & 0.93 & 0.97 & .44 \\
\hline 1.25 & 0.83 & 0.95 & .49 \\
\hline 0.53 & 1.29 & 0.22 & .39 \\
\hline 1.11 & 1.18 & 0.74 & .58 \\
\hline 0.78 & 0.72 & 0.76 & .58 \\
\hline 0.78 & 0.71 & 0.80 & .57 \\
\hline 0.90 & 1.01 & 0.78 & .84 \\
\hline 1.20 & 1.30 & 1.49 & .48 \\
\hline 1.39 & 1.36 & 1.27 & .40 \\
\hline 1.31 & 0.99 & 1.11 & .61 \\
\hline 1.25 & 0.86 & 1.17 & .54 \\
\hline 0.76 & 2.32 & 0.98 & .25 \\
\hline \multicolumn{4}{|c|}{$\beta$ Coefficient } \\
\hline
\end{tabular}

\begin{tabular}{rrrl}
\hline & & & \\
0.477 & 0.190 & 0.835 & .71 \\
-0.012 & -0.626 & 3.505 & .88 \\
0.034 & 0.154 & 0.237 & .34 \\
& & & \\
1.085 & 1.107 & 1.179 & .58 \\
-0.315 & 2.779 & 4.552 & .77 \\
1.011 & 1.066 & 1.104 & .81 \\
0.056 & 0.246 & 0.129 & .40 \\
\hline
\end{tabular}

not novel, with increased age being more frequently associated with the presence of such conditions, and the presence of an increasing number of conditions being associated with greater social and occupational impairment. Consistent with previous findings ${ }_{1}^{64}$ participants with more general medical conditions were more likely to have chronic depression, a more severe form of depression. This association raises the possibility that a greater physical disease burden leads to a greater psychiatric disease burden. With age, physical disease burden (number of general medical conditions) almost inevitably increases, which may leave patients more vulnerable to mood and anxiety symptoms. One interpretation, based on the later age of onset of MDD in patients with multiple general medical conditions, is that the addition of physical disease burden may be involved in the onset of MDD in vulnerable individuals. Another possibility is that general medical conditions lead to increased medical evaluations, giving rise to a higher probability for the recognition of somatic and nonsomatic MDD symptoms. As treatment guidelines for patients with general medical conditions and long-standing or recurrent depression are lacking, the best clinical decision may be to begin treatment with SSRI monotherapy given an a priori evaluation of predicted compatibility with concomitant medications, and then proceed to a trial of combination medications as needed.

The interpretation of the finding of difference in race is unclear and may be unique to the study sample. Interestingly, participants with more education had fewer general medical conditions, suggesting that education may have some protective impact in patients with depression. Perhaps education aids in providing better self-care and improved access to medical treatment, resulting in a reduction in the development of preventable conditions.

Our study had several limitations. The number of general medical conditions by antidepressant treatment was a planned secondary analysis; however, the granularity limits the statistical power of between-group comparisons. General medical conditions were self-reported. Patients had chronic or recurrent $\mathrm{MDD}$, or both, and may have had greater antidepressant treatment resistance than patients seen for a first episode of depression. Physicians and clinical research coordinators were not blinded to group affiliation, and as such, patients may have been inadvertently provided information leading to some degree of unblinding, although there is no evidence of this in the outcomes. Patients were recruited from primary care and psychiatric specialty care clinics, as opposed to internal medicine specialty clinics, and we excluded those not medically stable, not receiving adequate treatments for their general medical conditions, or both. It is possible that patients with more severe general medical conditions may have a differential outcome or tolerability profile if treated with antidepressant monotherapy as opposed to combination therapy. All patients received antidepressants in dosages in accord with current Food and Drug Administration guidelines; differential treatment response may become more apparent if medications 
Table 3. Selected Outcome Measures by Number of General Medical Conditions and Treatment

\begin{tabular}{|c|c|c|c|c|c|c|}
\hline \multirow[b]{3}{*}{ Measure } & \multicolumn{3}{|c|}{0 General Medical Conditions } & \multicolumn{3}{|c|}{1 General Medical Condition } \\
\hline & $\begin{array}{l}\text { BUP + ESC } \\
(n=115)\end{array}$ & $\begin{array}{l}\text { ESC }+ \text { PBO } \\
(n=112)\end{array}$ & $\begin{array}{l}\text { VEN + MIRT } \\
(n=101)\end{array}$ & $\begin{array}{l}\text { BUP }+ \text { ESC } \\
(n=50)\end{array}$ & $\begin{array}{l}\mathrm{ESC}+\mathrm{PBO} \\
(\mathrm{n}=56)\end{array}$ & $\begin{array}{l}\text { VEN + MIRT } \\
(n=52)\end{array}$ \\
\hline & \multicolumn{3}{|c|}{ No. (\%) } & \multicolumn{3}{|c|}{ No. (\%) } \\
\hline \multicolumn{7}{|l|}{ Week 12} \\
\hline Early termination & 37 (32.2) & $28(25.0)$ & $25(24.8)$ & $14(28.0)$ & $15(26.8)$ & $18(34.6)$ \\
\hline Remission ${ }^{b}$ & $44(38.6)$ & $45(40.2)$ & $40(40.0)$ & $19(38.0)$ & $21(37.5)$ & $15(28.8)$ \\
\hline Responsec & $55(50.0)$ & $60(56.6)$ & $57(58.2)$ & $29(58.0)$ & $30(53.6)$ & $18(37.5)$ \\
\hline \multicolumn{7}{|l|}{ Last FIBSER Burden } \\
\hline No impairment & $59(54.1)$ & $58(54.7)$ & $46(47.4)$ & $29(59.2)$ & $25(47.2)$ & $26(53.1)$ \\
\hline Minimal/mild & $38(34.9)$ & $41(38.7)$ & $38(39.2)$ & $16(32.7)$ & $24(45.3)$ & $12(24.5)$ \\
\hline Moderate/marked & $8(7.3)$ & $5(4.7)$ & $12(12.4)$ & $3(6.1)$ & $3(5.7)$ & $9(18.4)$ \\
\hline Severe/intolerable & $4(3.7)$ & $2(1.9)$ & $1(1.0)$ & $1(2.0)$ & $1(1.9)$ & $2(4.1)$ \\
\hline \multicolumn{7}{|l|}{ Week 28} \\
\hline Early termination & $45(39.1)$ & $42(37.5)$ & $36(35.6)$ & $17(34.0)$ & $19(33.9)$ & $24(46.2)$ \\
\hline Remission ${ }^{b}$ & $56(50.0)$ & $58(52.3)$ & $42(42.4)$ & $23(46.0)$ & $25(44.6)$ & $21(40.4)$ \\
\hline Responsec & $64(59.3)$ & $66(62.9)$ & $58(59.8)$ & $33(66.0)$ & $35(62.5)$ & $25(52.1)$ \\
\hline \multicolumn{7}{|l|}{ Last FIBSER Burden } \\
\hline No impairment & $68(61.8)$ & $66(62.3)$ & $49(50.5)$ & $30(61.2)$ & $34(64.2)$ & $27(55.1)$ \\
\hline Minimal/mild & $30(27.3)$ & $31(29.2)$ & $33(34.0)$ & $16(32.7)$ & $15(28.3)$ & $11(22.4)$ \\
\hline Moderate/marked & $8(7.3)$ & $7(6.6)$ & $14(14.4)$ & $3(6.1)$ & $3(5.7)$ & $10(20.4)$ \\
\hline \multirow[t]{2}{*}{ Severe/intolerable } & $4(3.6)$ & $2(1.9)$ & $1(1.0)$ & - & $1(1.9)$ & $1(2.0)$ \\
\hline & \multicolumn{3}{|c|}{ Mean (SD) } & \multicolumn{3}{|c|}{ Mean (SD) } \\
\hline \multicolumn{7}{|l|}{ Week 12} \\
\hline Last QIDS-SR 16 & $7.7(4.9)$ & $7.7(5.4)$ & $8.0(5.7)$ & $8.0(5.2)$ & $7.1(4.7)$ & $9.4(5.8)$ \\
\hline$\%$ QIDS-SR $_{16}$ reduction & $-45(35.4)$ & $-49(35.9)$ & $-50(33.0)$ & $-47(31.8)$ & $-52(28.0)$ & $-41(30.7)$ \\
\hline \multicolumn{7}{|l|}{ Week 28} \\
\hline Last QIDS-SR 16 & $6.7(4.8)$ & $7.0(5.6)$ & $8.2(6.1)$ & $7.1(5.5)$ & $6.5(4.3)$ & $8.4(5.8)$ \\
\hline$\%$ QIDS-SR $_{16}$ reduction & $-51(38.1)$ & $-54(34.3)$ & $-50(33.5)$ & $-54(32.3)$ & $-56(27.3)$ & $-46(32.1)$ \\
\hline \multicolumn{7}{|c|}{$\begin{array}{l}\text { BUP = bupropion-SR; ESC = escitalopram; FIBSER = Frequency, Intensity, and Burden of Side Effects Rating; MIRT = mirtazapine; PBO = Placebo; QIDS-SR } 16=16 \text {-item } \\
\text { Quick Inventory of Depressive Symptomatology-Self-Report; VEN = venlafaxine-XR. }\end{array}$} \\
\hline \multicolumn{7}{|c|}{ Note: QIDS-SR ${ }_{16}$ scores range from 0 to 27 , with higher scores indicating greater levels of depression. } \\
\hline \multirow{2}{*}{\multicolumn{7}{|c|}{$\begin{array}{l}\text { a } P \text { value associated with the number of general medical conditions by treatment interaction term. } \\
\text { b Patients were classified as being in remission if their last } 2 \text { QIDS-SR } \text { SI }_{16} \text { scores were less than } 6 \text {. }\end{array}$}} \\
\hline & \multicolumn{6}{|c|}{$\begin{array}{l}\text { b Patients were classified as being in remission if their last } 2 \text { QIDS-SR }_{16} \text { Scores were less than } 6 \text {. } \\
\text { c Patients were classified as having a response if they had a decrease in OIDS-SR } 1 \text { score of at least }\end{array}$} \\
\hline
\end{tabular}

are given at higher dosages. ${ }^{65}$ Additionally, several of the symptom criteria for MDD (decreased energy, sleep and appetite irregularities) may be influenced by general medical conditions. The overlap in symptoms between MDD and these conditions may also be partially responsible for an increase in diagnosis of MDD in those with general medical conditions, as well as an increase in depressive severity scores.

In conclusion, patients with and without general medical conditions can be safely and effectively treated for MDD with antidepressant medications with no additional adverse effect or tolerability burden for the former. In patients with general medical conditions and comorbid chronic MDD (lasting $\geq 2$ years), recurrent $\mathrm{MDD}$, or both, no additional benefit was seen for combination antidepressant therapy vs SSRI monotherapy.
To read or post commentaries in response to this article, see it online at http://www.annfammed.org/content/10/1/23.

Key words: Antidepressant; depression; mood disorder; general medical condition; comorbidities; mental health; primary care; practicebased research

Submitted April 1, 2011; submitted, revised, July 13, 2011; accepted August 8, 2011.

Conflicts of interest: Dr Morris has no disclosures to report. Dr Budhwar has no disclosures to report. Dr Husain has received grant support from National Institutes of Health/National Institute of Mental Health, Stanley Foundation, Cyberonics, Neuronetics, St Jude Medical (ANS), and MagStim; he has also been on the speakers bureaus for BristolMyers Squibb, Forest, AstraZeneca, and Novartis. Dr Wisniewski has been a consultant for Cyberonics, Inc, ImaRx Therapeutics, Inc, BristolMyers Squibb, Organon, and Case-Western University. Dr Kurian has received research support from Targacept, Inc, and Pfizer. Mr Luther has no disclosures to report. Dr Kerber has no disclosures to report. Dr 


\begin{tabular}{|c|c|c|c|c|c|c|}
\hline \multicolumn{3}{|c|}{2 General Medical Conditions } & \multicolumn{3}{|c|}{$\geq 3$ General Medical Conditions } & \multirow[b]{3}{*}{$P$ Value $^{a}$} \\
\hline $\begin{array}{c}\text { BUP + ESC } \\
(n=38)\end{array}$ & $\begin{array}{c}\mathrm{ESC}+\mathrm{PBO} \\
(\mathrm{n}=23)\end{array}$ & $\begin{array}{c}\text { VEN + MIRT } \\
(\mathrm{n}=37)\end{array}$ & $\begin{array}{c}\text { BUP + ESC } \\
(n=18)\end{array}$ & $\begin{array}{c}\mathrm{ESC}+\mathrm{PBO} \\
(\mathrm{n}=31)\end{array}$ & $\begin{array}{c}\text { VEN + MIRT } \\
(\mathrm{n}=30)\end{array}$ & \\
\hline \multicolumn{3}{|c|}{ No. (\%) } & \multicolumn{3}{|c|}{ No. (\%) } & \\
\hline $11(28.9)$ & $6(26.1)$ & $8(21.6)$ & $8(44.8)$ & $5(16.1)$ & $6(20.0)$ & .53 \\
\hline $15(40.5)$ & $6(26.1)$ & $14(38.9)$ & $4(22.2)$ & $9(29.0)$ & $10(33.3)$ & .77 \\
\hline \multirow[t]{2}{*}{$21(56.8)$} & $11(47.8)$ & $19(55.9)$ & $6(33.3)$ & $12(38.7)$ & $16(53.3)$ & .19 \\
\hline & & & & & & .71 \\
\hline $21(60.0)$ & $14(63.6)$ & $16(47.1)$ & $9(56.3)$ & $20(71.4)$ & $21(72.4)$ & - \\
\hline $10(28.6)$ & $3(13.6)$ & $16(47.1)$ & $5(31.3)$ & $6(21.4)$ & $6(20.7)$ & - \\
\hline $3(8.6)$ & $4(18.2)$ & $1(2.9)$ & - & $2(7.1)$ & $1(3.4)$ & - \\
\hline $1(2.9)$ & $1(4.5)$ & $1(2.9)$ & $2(12.5)$ & - & $1(3.4)$ & - \\
\hline $14(36.8)$ & $9(39.1)$ & $14(37.8)$ & $8(44.4)$ & $7(22.6)$ & $8(26.7)$ & .58 \\
\hline $15(39.5)$ & $8(34.8)$ & $12(33.3)$ & $7(38.9)$ & $10(32.3)$ & $15(50.0)$ & .69 \\
\hline \multirow[t]{2}{*}{$20(52.6)$} & $13(56.5)$ & 18 (52.9) & $8(44.4)$ & $15(48.4)$ & $19(63.3)$ & .63 \\
\hline & & & & & & .96 \\
\hline $20(57.1)$ & $14(60.9)$ & $17(50.0)$ & $10(62.5)$ & $21(75.0)$ & $18(62.1)$ & - \\
\hline $11(31.4)$ & $6(26.1)$ & $13(38.2)$ & $3(18.8)$ & $7(25.0)$ & $7(24.1)$ & - \\
\hline $3(8.6)$ & $2(8.7)$ & $4(11.8)$ & $1(6.3)$ & - & $3(10.3)$ & - \\
\hline $1(2.9)$ & $1(4.3)$ & - & $2(12.5)$ & - & $1(3.4)$ & - \\
\hline \multicolumn{3}{|c|}{ Mean (SD) } & \multicolumn{3}{|c|}{ Mean (SD) } & \\
\hline $8.5(6.7)$ & $9.1(5.5)$ & $8.2(6.0)$ & $9.8(5.1)$ & $9.4(4.9)$ & $8.4(5.3)$ & .44 \\
\hline$-47(33.6)$ & $-42(25.1)$ & $-42(46.1)$ & $-33(40.0)$ & $-37(33.3)$ & $-45(34.9)$ & .48 \\
\hline $8.4(6.7)$ & $8.2(6.1)$ & $8.5(5.9)$ & $9.3(4.9)$ & $9.0(5.5)$ & $6.9(5.4)$ & .18 \\
\hline$-48(34.8)$ & $-48(30.8)$ & $-40(43.3)$ & $-34(38.9)$ & $-40(35.8)$ & $-54(40.7)$ & .28 \\
\hline
\end{tabular}

Rush has received consultant fees from Advanced Neuromodulation Systems, AstraZeneca, Best Practice Project Management, Bristol-Myers Squibb/Otsuka, Cyberonics, Forest Pharmaceuticals, Gerson Lehrman Group, GlaxoSmithKline, Jazz Pharmaceuticals, Magellan Health Services, Merck \& Company, Neuronetics, Novartis Pharmaceuticals, Ono Pharmaceuticals, Organon, Otsuka Pharmaceuticals, Pamlab, Pfizer, Transcept Pharmaceuticals, Urban Institute, and Wyeth Ayerst; speaking fees from Cyberonics Inc, Forest Laboratories, GlaxoSmithKline, and Otsuka; royalties from Guilford Publications and Healthcare Technology Systems; and research support from National Institute of Mental Health and the Stanley Medical Research Institute; he has also owned shares of stock in Pfizer. Dr Trivedi has been a consultant for Abbott Laboratories, Inc, Akzo (Organon Pharmaceuticals Inc), AstraZeneca, Bayer, Bristol-Myers Squibb, Cephalon, Inc, Cyberonics, Inc, Eli Lilly \& Company, Fabre-Kramer Pharmaceuticals, Inc, Forest Pharmaceuticals, GlaxoSmithKline, Janssen Pharmaceutica Products, LP, Johnson \& Johnson PRD, Meade Johnson, Neuronetics, Parke-Davis Pharmaceuticals, Inc, Pfizer, Inc, Pharmacia \& Upjohn, Sepracor, Solvay Pharmaceuticals, Inc, VantagePoint, and Wyeth-Ayerst Laboratories; he has also served on speakers bureaus for Abdi Brahim, Akzo (Organon Pharmaceuticals Inc), Bristol-Myers Squibb, Cephalon, Inc, Cyberonics, Inc, Forest Phar- maceuticals, GlaxoSmithKline, Janssen Pharmaceutica Products, LP, Eli Lilly \& Company, Pharmacia \& Upjohn, Solvay Pharmaceuticals, Inc, and Wyeth-Ayerst Laboratories; and he has also received grant support from Bristol-Myers Squibb, Cephalon, Inc, Corcept Therapeutics, Inc, Cyberonics, Inc, Eli Lilly \& Company, Forest Pharmaceuticals, GlaxoSmithKline, Janssen Pharmaceutica, Merck, National Institute of Mental Health, National Alliance for Research in Schizophrenia and Depression, Novartis, Pfizer Inc, Pharmacia \& Upjohn, Predix Pharmaceuticals, Solvay Pharmaceuticals, Inc, and Wyeth-Ayerst Laboratories.

Funding support: This project was funded by the National Institute of Mental Health (NIMH) under contract N01MH90003 to University of Texas Southwestern Medical Center at Dallas (PIs A.J. Rush, M.H. Trivedi).

Disclaimer: The content of this publication does not necessarily reflect the views or policies of the Department of Health and Human Services, nor does mention of trade names, commercial products, or organizations imply endorsement by the US government. The NIMH had no role in the drafting or review of the manuscript, nor in the collection or analysis of the data. 
Acknowledgments: We would like to thank the clinical staff at each clinical site for their assistance with this project; all of the study participants who contributed to this project; and Eric Nestler, MD, PhD, Lou and Ellen McGinley Distinguished Professor and Past Chairman, Department of Psychiatry, University of Texas Southwestern Medical Center, as well as Carol A. Tamminga, MD, Communities Foundation of Texas, Inc, Chair in Brain Science, and Chair, Department of Psychiatry, University of Texas Southwestern Medical Center for their administrative support. We would also like to acknowledge the editorial support of Jon Kilner, MS, MA (Pittsburgh, Pennsylvania). We appreciate the support of Forest Pharmaceuticals Inc, GlaxoSmithKline, Organon Inc, and Wyeth Pharmaceuticals in providing medications at no cost for this trial.

Trial registry: ClinicalTrials.gov NCT00590863.

\section{References}

1. Depression Guideline Panel. Clinical Practice Guideline, Number 5: Depression in Primary Care, Volume 1: Detection and Diagnosis. Rockville, MD: US Department of Health and Human Services, Public Health Service, Agency for Health Care Policy and Research; 1993. AHCPR publication 93-0550.

2. Cornwall PL, Scott J. Partial remission in depressive disorders. Acta Psychiatr Scand. 1997;95(4):265-271.

3. Keller MB, Klein DN, Hirschfeld RMA, et al. Results of the DSM-IV mood disorders field trial. Am J Psychiatry. 1995;152(6):843-849.

4. Depression Guideline Panel. Clinical Practice Guideline, Number 5: Depression in Primary Care: Volume 2: Treatment of Major Depression. Rockville, MD: US Department of Health and Human Services, Public Health Service, Agency for Health Care Policy and Research; 1993. AHCPR publication 93-0551.

5. Lin EH, Katon WJ, VonKorff M, et al. Relapse of depression in primary care. Rate and clinical predictors. Arch Fam Med. 1998;7(5): 443-449.

6. Schulberg HC, Katon W, Simon GE, Rush AJ. Treating major depression in primary care practice: an update of the Agency for Health Care Policy and Research Practice Guidelines. Arch Gen Psychiatry. 1998;55(12):1121-1127.

7. World Health Organization. The Global Burden of Disease: 2004 Update. Geneva, Switzerland: WHO; 2008.

8. Burg MM, Abrams D. Depression in chronic medical illness: the case of coronary heart disease. J Clin Psychol. 2001;57(11):1323-1337.

9. Fifield J, Tennen H, Reisine S, McQuillan J. Depression and the long-term risk of pain, fatigue, and disability in patients with rheumatoid arthritis. Arthritis Rheum. 1998;41(10):1851-1857.

10. Finkelstein EA, Bray JW, Chen $\mathrm{H}$, et al. Prevalence and costs of major depression among elderly claimants with diabetes. Diabetes Care. 2003;26(2):415-420.

11. Horikawa N, Yamazaki T, Izumi N, Uchihara M. Incidence and clinical course of major depression in patients with chronic hepatitis type $C$ undergoing interferon-alpha therapy: a prospective study. Gen Hosp Psychiatry. 2003;25(1):34-38.

12. Coulehan JL, Schulberg HC, Block MR, Janosky JE, Arena VC. Medical comorbidity of major depressive disorder in a primary medical practice. Arch Intern Med. 1990;150(11):2363-2367.

13. Wells KB, Rogers W, Burnam A, Greenfield S, Ware JE Jr. How the medical comorbidity of depressed patients differs across health care settings: results from the Medical Outcomes Study. Am J Psychiatry. 1991;148(12):1688-1696.

14. Endicott J. Measurement of depression in patients with cancer. Cancer. 1984;53(10 Suppl):2243-2249.

15. Kathol RG, Mutgi A, Williams J, Clamon G, Noyes R Jr. Diagnosis of major depression in cancer patients according to four sets of criteria. Am J Psychiatry. 1990;147(8):1021-1024.
16. Koenig HG, George LK, Peterson BL, Pieper CF. Depression in medically ill hospitalized older adults: prevalence, characteristics, and course of symptoms according to six diagnostic schemes. Am J Psychiatry. 1997;154(10):1376-1383.

17. Robinson WD, Geske JA, Prest LA, Barnacle R. Depression treatment in primary care. J Am Board Fam Pract. 2005;18(2):79-86.

18. Patten SB, Beck CA, Kassam A, Williams JV, Barbui C, Metz LM. Long-term medical conditions and major depression: strength of association for specific conditions in the general population. Can J Psychiatry. 2005;50(4):195-202.

19. Noël PH, Williams JW Jr, Unützer J, et al. Depression and comorbid illness in elderly primary care patients: impact on multiple domains of health status and well-being. Ann Fam Med. 2004;2(6):555-562.

20. Evans DL, Charney DS, Lewis L, et al. Mood disorders in the medically ill: scientific review and recommendations. Biol Psychiatry. 2005;58(3):175-189.

21. Solberg LI, Crain AL, Sperl-Hillen JM, Hroscikoski MC, Engebretson $\mathrm{KI}, \mathrm{O}^{\prime}$ Connor PJ. Care quality and implementation of the chronic care model: a quantitative study. Ann Fam Med. 2006;4(4):310-316.

22. Bayliss EA, Ellis JL, Steiner JF. Barriers to self-management and quality-of-life outcomes in seniors with multimorbidities. Ann Fam Med. 2007;5(5):395-402.

23. Nilsson FM, Kessing LV, Sørensen TM, Andersen PK, Bolwig TG. Major depressive disorder in Parkinson's disease: a register-based study. Acta Psychiatr Scand. 2002;106(3):202-211.

24. Bogner HR, de Vries HF. Integration of depression and hypertension treatment: a pilot, randomized controlled trial. Ann Fam Med. 2008;6(4):295-301.

25. Post-Myocardial Infarction Depression Clinical Practice Guideline Panel. AAFP guideline for the detection and management of postmyocardial infarction depression. Ann Fam Med. 2009;7(1):71-79.

26. Yates WR, Mitchell J, Rush AJ, et al. Clinical features of depressed outpatients with and without co-occurring general medical conditions in STAR*D. Gen Hosp Psychiatry. 2004;26(6):421-429.

27. Yates WR, Mitchell J, John Rush A, et al. Clinical features of depression in outpatients with and without co-occurring general medical conditions in STAR * D: confirmatory analysis. Prim Care Companion J Clin Psychiatry. 2007;9(1):7-15.

28. Rush AJ, Trivedi MH, Stewart JW, et al. Combining Medications to Enhance Depression Outcomes (CO-MED): acute and long-term outcomes of a single-blind randomized study. Am J Psychiatry. 2011; 168(7):689-701.

29. Ascher JA, Cole JO, Colin JN, et al. Bupropion: a review of its mechanism of antidepressant activity. J Clin Psychiatry. 1995;56(9):395-401.

30. Bodkin JA, Lasser RA, Wines JD Jr, Gardner DM, Baldessarini RJ. Combining serotonin reuptake inhibitors and bupropion in partial responders to antidepressant monotherapy. J Clin Psychiatry. 1997: 58(4):137-145

31. DeBattista C, Solvason HB, Poirier J, Kendrick E, Schatzberg AF. A prospective trial of bupropion SR augmentation of partial and nonresponders to serotonergic antidepressants. J Clin Psychopharmacol. 2003;23(1):27-30.

32. Haddjeri N, Blier P, de Montigny C. Noradrenergic modulation of central serotonergic neurotransmission: acute and long-term actions of mirtazapine. Int Clin Psychopharmacol. 1995;10(Suppl 4):11-17.

33. American Psychiatric Association. Diagnostic and Statistical Manual of Mental Disorders. 4th ed, Text Revision. Arlington, VA: American Psychiatric Association; 2000.

34. Sheehan DV, Lecrubier Y, Sheehan KH, et al. The Mini-International Neuropsychiatric Interview (M.I.N.I.): the development and validation of a structured diagnostic psychiatric interview for DSM-IV and ICD-10. J Clin Psychiatry. 1998;59(Suppl 20):22-33, quiz 34-57.

35. Hamilton M. A rating scale for depression. J Neurol Neurosurg Psychiatry. 1960;23:56-62. 
36. Trivedi MH, Rush AJ, Wisniewski SR, et al; STAR*D Study Team. Evaluation of outcomes with citalopram for depression using measurement-based care in STAR*D: implications for clinical practice. Am J Psychiatry. 2006;163(1):28-40.

37. Rush AJ, Trivedi MH, Ibrahim HM, et al. The 16-item Quick Inventory of Depressive Symptomatology (QIDS), clinician rating (QIDSC), and self-report (QIDS-SR): a psychometric evaluation in patients with chronic major depression. Biol Psychiatry. 2003;54(5):573-583. Erratum p 585.

38. Wisniewski SR, Rush AJ, Balasubramani GK, Trivedi MH, Nierenberg $A A$; for the STARD Investigators. Self-rated global measure of the frequency, intensity, and burden of side effects. J Psychiatr Pract. 2006;12(2):71-79.

39. Levine J, Schooler NR. SAFTEE: a technique for the systematic assessment of side effects in clinical trials. Psychopharmacol Bull. 1986;22(2):343-381.

40. Wisniewski SR, Eng H, Meloro L, et al. Web-based communications and management of a multi-center clinical trial: the Sequenced Treatment Alternatives to Relieve Depression (STAR*D) project. Clin Trials. 2004;1(4):387-398.

41. Fava M. Augmentation and combination strategies in treatmentresistant depression. J Clin Psychiatry. 2001;62(Suppl 18):4-11.

42. Papakostas Gl, Petersen TJ, Kinrys G, et al. Aripiprazole augmentation of selective serotonin reuptake inhibitors for treatment-resistant major depressive disorder. J Clin Psychiatry. 2005;66(10):1326-1330.

43. Leuchter AF, Lesser IM, Trivedi MH, et al. An open pilot study of the combination of escitalopram and bupropion-SR for outpatients with major depressive disorder. J Psychiatr Pract. 2008;14(5):271-280.

44. McGrath PJ, Stewart JW, Fava M, et al. Tranylcypromine versus venlafaxine plus mirtazapine following three failed antidepressant medication trials for depression: a STAR*D report. Am J Psychiatry. 2006;163(9):1531-1541, quiz 1666.

45. Zimmerman M, Mattia JI. A self-report scale to help make psychiatric diagnoses: the Psychiatric Diagnostic Screening Questionnaire. Arch Gen Psychiatry. 2001;58(8):787-794

46. Rush AJ, Zimmerman M, Wisniewski SR, et al. Comorbid psychiatric disorders in depressed outpatients: demographic and clinical features. J Affect Disord. 2005;87(1):43-55.

47. Sangha O, Stucki G, Liang MH, Fossel AH, Katz JN. The Self-Administered Comorbidity Questionnaire: a new method to assess comorbidity for clinical and health services research. Arthritis Rheum. 2003;49(2):156-163.

48. Mundt JC, Marks IM, Shear MK, Greist JH. The Work and Social Adjustment Scale: a simple measure of impairment in functioning. Br J Psychiatry. 2002;180:461-464.

49. Schulberg HC, McClelland M, Gooding W. Six-month outcomes for medical patients with major depressive disorders. J Gen Intern Med. 1987;2(5):312-317

50. Keitner GI, Ryan CE, Miller IW, Kohn R, Epstein NB. 12-month outcome of patients with major depression and comorbid psychiatric or medical illness (compound depression). Am J Psychiatry. 1991:148(3):345-350.
51. Cole MG, Bellavance F, Mansour A. Prognosis of depression in elderly community and primary care populations: a systematic review and meta-analysis. Am J Psychiatry. 1999;156(8):1182-1189.

52. Brown C, Schulberg HC, Prigerson HG. Factors associated with symptomatic improvement and recovery from major depression in primary care patients. Gen Hosp Psychiatry. 2000;22(4):242-250.

53. Steffens DC, McQuoid DR, Krishnan KRR. The Duke Somatic Treatment Algorithm for Geriatric Depression (STAGED) approach. Psychopharmacol Bull. 2002;36(2):58-68.

54. Koike AK, Unützer J, Wells KB. Improving the care for depression in patients with comorbid medical illness. Am J Psychiatry. 2002;159 (10):1738-1745.

55. Dickinson LM, Rost K, Nutting PA, Elliott CE, Keeley RD, Pincus H. $\mathrm{RCT}$ of a care manager intervention for major depression in primary care: 2-year costs for patients with physical vs psychological complaints. Ann Fam Med. 2005;3(1):15-22.

56. Klinkman MS, Bauroth S, Fedewa S, et al. Long-term clinical outcomes of care management for chronically depressed primary care patients: a report from the depression in primary care project. Ann Fam Med. 2010;8(5):387-396.

57. Rost K, Nutting P, Smith JL, Elliott CE, Dickinson M. Managing depression as a chronic disease: a randomised trial of ongoing treatment in primary care. BMJ. 2002;325(7370):934.

58. Katon W, Von Korff M, Lin E, et al. Stepped collaborative care for primary care patients with persistent symptoms of depression: a randomized trial. Arch Gen Psychiatry. 1999;56(12):1109-1115.

59. Katon W, Von Korff M, Lin E, et al. Collaborative management to achieve treatment guidelines. Impact on depression in primary care. JAMA. 1995;273(13):1026-1031.

60. Rost K, Nutting P, Smith J, Werner J, Duan N. Improving depression outcomes in community primary care practice: a randomized trial of the quEST intervention. Quality Enhancement by Strategic Teaming. J Gen Intern Med. 2001;16(3):143-149.

61. Wells KB, Sherbourne C, Schoenbaum M, et al. Impact of disseminating quality improvement programs for depression in managed primary care: a randomized controlled trial. JAMA. 2000;283(2): 212-220.

62. Nutting PA, Gallagher K, Riley K, et al. Care management for depression in primary care practice: findings from the RESPECTDepression trial. Ann Fam Med. 2008;6(1):30-37.

63. Gaynes BN, Rush AJ, Trivedi MH, et al. Major depression symptoms in primary care and psychiatric care settings: a cross-sectional analysis. Ann Fam Med. 2007;5(2):126-134.

64. Hays JC, Krishnan KR, George LK, Pieper CF, Flint EP, Blazer DG. Psychosocial and physical correlates of chronic depression. Psychiatry Res. 1997;72(3):149-159.

65. Blier P, Ward HE, Tremblay P, Laberge L, Hébert C, Bergeron R. Combination of antidepressant medications from treatment initiation for major depressive disorder: a double-blind randomized study. Am J Psychiatry. 2010;167(3):281-288. 